\title{
Continental-scale suppression of an invasive pest by a host- specific parasitoid underlines both environmental and economic benefits of arthropod biological control
}

Kris AG Wyckhuys ${ }^{\text {Corresp., }} 1,2,3,4$, Prapit Wongtiem ${ }^{5}$, Aunu Rauf ${ }^{6}$, Anchana Thancharoen ${ }^{7}$, George E Heimpel ${ }^{8}$ Nhung TT Le ${ }^{9}$, Muhammad Zainal Fanani ${ }^{6}$ ， Geoff M Gurr ${ }^{4,10}$ ， Jonathan G Lundgren ${ }^{11}$ ， Dharani D Burra ${ }^{12}$, Leo K Palao ${ }^{12}$ ， Glenn Hyman ${ }^{13}$ ， Ignazio Graziosi ${ }^{14,15}{ }^{15}$ Vi X Le ${ }^{9}$ ， Matthew JW Cock ${ }^{16}$, Teja Tscharntke ${ }^{17}$, Steve D Wratten ${ }^{4,18}$ ， Liem V Nguyen ${ }^{9}$ ， Minsheng You ${ }^{4}$ ，Yanhui Lu ${ }^{19}$ ， Johannes W Ketelaar ${ }^{20}$, Georg Goergen ${ }^{21}$, Peter Neuenschwander ${ }^{21}$

${ }^{1}$ CGIAR Program on Roots, Tubers and Banana, International Center for Tropical Agriculture, Hanoi, Vietnam

2 School of Biological Sciences, University of Queensland, Brisbane, Australia

3 Institute of Insect Sciences, Zhejiang University (浙江大学化工系), Hangzhou, China

4 Institute of Applied Ecology, Fujian Agriculture \& Forestry University, Fuzhou, Fujian, China

5 Rayong Field Crops Research Center, Thai Department of Agriculture, Rayong, Thailand

6 Bogor Agricultural University, Bogor, Indonesia

7 Kasetsart University, Bangkok, Thailand

8 University of Minnesota, Minneapolis, United States

9 Plant Protection Research Institute, Hanoi, Việt Nam

10 Charles Sturt University, Orange, Australia

11 Ecdysis Foundation, Estelline, United States

12 International Center for Tropical Agriculture CIAT, Hanoi, Viet Nam

13 International Center for Tropical Agriculture CIAT, Cali, Colombia

14 University of Kentucky, Lexington, United States

15 World Agroforestry Center ICRAF, Nairobi, Kenya

16 CABI, Wallingford, United Kingdom

17 University of Goettingen, Goettingen, Germany

18 Lincoln University, Christchurch, New Zealand

19 China Academy of Agricultural Sciences, Beijing, China

20 Food and Agriculture Organization, Bangkok, Thailand

21 International Institute for Tropical Agriculture, Cotonou, Benin

Corresponding Author: Kris AG Wyckhuys

Email address: kagwyckhuys@gmail.com

Biological control, a globally-important ecosystem service, can provide long-term and broad-scale suppression of invasive pests, weeds and pathogens in natural, urban and agricultural environments. Following (few) historic cases that led to sizeable environmental up-sets, the discipline of arthropod biological control has -over the past three decadesevolved and matured. Now, by deliberately taking into account the ecological risks associated with the planned introduction of insect natural enemies, immense environmental and societal benefits can be gained. In this study, we document and analyze a successful case of biological control against the cassava mealybug, Phenacoccus manihoti (Hemiptera: Pseudococcidae) which invaded Southeast Asia in 2008, where it 
caused substantial crop losses and triggered 2- to 3-fold surges in agricultural commodity prices. In 2009, the host-specific parasitoid Anagyrus lopezi (Hymenoptera: Encyrtidae) was released in Thailand and subsequently introduced into neighboring Asian countries. Drawing upon continental-scale insect surveys, multi-year population studies and (fieldlevel) experimental assays, we show how $A$. lopezi attained intermediate to high parasitism rates across diverse agro-ecological contexts. Driving mealybug populations below non-damaging levels over a broad geographical area, $A$. lopezi allowed yield recoveries up to 10.0 t/ha and provided biological control services worth several hundred dollars per ha (at local farm-gate prices) in Asia's 4-million ha cassava crop. Our work provides lessons to invasion science and crop protection worldwide, accentuates the importance of (judiciously-implemented) biological control for insect pest management, and highlights its potentially large socio-economic benefits to agricultural sustainability in the face of a debilitating invasive pest. In times of unrelenting insect invasions, surging pesticide use and accelerating biodiversity loss across the globe, this study unequivocally demonstrates how biological control - as a pure public good endeavor - constitutes a powerful, cost-effective and environmentally-responsible solution for invasive species mitigation. 
1 For submission to PeerJ

2

3

4

5

6

7

8

9

10

11

12

13

14
Send correspondence to:

Kris A. G. Wyckhuys

Chinese Academy of Agricultural Sciences

2 West Yuanmingyuan Rd., Beijing, 100193, P. R. China

Tel:+86-10-62813685

Contact:kagwyckhuys@gmail.com

\section{Continental-scale suppression of an invasive pest by a host-specific parasitoid underlines both environmental and economic benefits of arthropod biological control}

\section{Running head: Biocontrol of the cassava mealybug in Asia}

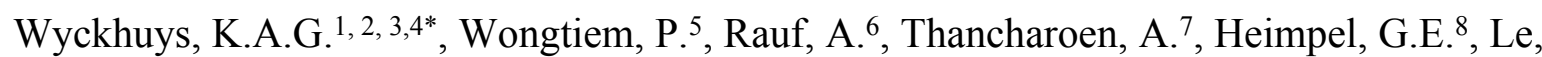
N.T.T. ${ }^{9}$, Fanani, M.Z. ${ }^{6}$, Gurr, G.M. ${ }^{2,10}$, Lundgren, J.G. ${ }^{11}$, Burra, D.D. ${ }^{12}$, Palao, L.K. ${ }^{12}$, Hyman, G. ${ }^{13}$, Graziosi, I. ${ }^{14,15}$, Le, V.X. ${ }^{9}$, Cock, M.J.W. ${ }^{16}$, Tscharntke, T. ${ }^{17}$, Wratten, S.D. ${ }^{2,18}$, Nguyen, L.V. ${ }^{9}$, You, M.S. ${ }^{2}$, Lu, Y.H. ${ }^{19}$, Ketelaar, J.W. ${ }^{20}$, Goergen, G. ${ }^{21}$, Neuenschwander, P. ${ }^{21}$

1. CGIAR Program on Roots, Tubers and Banana (CRP-RTB), International Center for Tropical Agriculture CIAT, Hanoi, Vietnam;

2. International Joint Research Laboratory on Ecological Pest Management, Fuzhou, China;

3. School of Biological Sciences, University of Queensland, Brisbane, Australia;

4. Institute of Insect Sciences, Zhejiang University, Hangzhou, China;

5. Thai Department of Agriculture (DoA), Bangkok, Thailand;

6. Bogor Agricultural University, Bogor, Indonesia

7. Kasetsart University, Bangkok, Thailand;

8. University of Minnesota, Minneapolis, Minnesota (USA);

9. Plant Protection Research Institute (PPRI), Vietnam Academy of Agricultural Sciences VAAS, Hanoi, Vietnam;

10. Charles Sturt University, Orange, Australia;

11. Ecdysis Foundation, Estelline, South Dakota (USA);

12. International Center for Tropical Agriculture CIAT, Hanoi, Vietnam;

13. International Center for Tropical Agriculture CIAT, Cali, Colombia;

14. University of Kentucky, Lexington, Kentucky (USA);

15. World Agroforestry Center (ICRAF), Nairobi, Kenya;

16. CABI, Egham, UK;

17. Gottingen University, Gottingen, Germany;

18. Lincoln University, Christchurch, New Zealand;

19. China Academy of Agricultural Sciences IPP-CAAS, Beijing, China;

20. Food and Agriculture Organization FAO, Bangkok, Thailand;

21. International Institute for Tropical Agriculture IITA, Cotonou, Benin; 


\section{Abstract}

44 Biological control, a globally-important ecosystem service, can provide long-term and broad-

45 scale suppression of invasive pests, weeds and pathogens in natural, urban and agricultural

46 environments. Following (few) historic cases that led to sizeable environmental up-sets, the

47 discipline of arthropod biological control has -over the past three decades- evolved and matured.

48 Now, by deliberately taking into account the ecological risks associated with the planned

49 introduction of insect natural enemies, immense environmental and societal benefits can be

50 gained. In this study, we document and analyze a successful case of biological control against the

51 cassava mealybug, Phenacoccus manihoti (Hemiptera: Pseudococcidae) which invaded

52 Southeast Asia in 2008, where it caused substantial crop losses and triggered 2- to 3-fold surges

53 in agricultural commodity prices. In 2009, the host-specific parasitoid Anagyrus lopezi

54 (Hymenoptera: Encyrtidae) was released in Thailand and subsequently introduced into

55 neighboring Asian countries. Drawing upon continental-scale insect surveys, multi-year

56 population studies and (field-level) experimental assays, we show how A. lopezi attained

57 intermediate to high parasitism rates across diverse agro-ecological contexts. Driving mealybug

58 populations below non-damaging levels over a broad geographical area, $A$. lopezi allowed yield

59 recoveries up to 10.0 t/ha and provided biological control services worth several hundred dollars

60 per ha (at local farm-gate prices) in Asia's 4-million ha cassava crop. Our work provides lessons

61 to invasion science and crop protection worldwide, accentuates the importance of (judiciously-

62 implemented) biological control for insect pest management, and highlights its potentially large

63 socio-economic benefits to agricultural sustainability in the face of a debilitating invasive pest. In

64 times of unrelenting insect invasions, surging pesticide use and accelerating biodiversity loss

65 across the globe, this study unequivocally demonstrates how biological control - as a pure public 
66 good endeavor - constitutes a powerful, cost-effective and environmentally-responsible solution

67 for invasive species mitigation.

68

69

70 


\section{Introduction}

72

73 Biological control is a globally-important ecosystem service, and plays a pivotal role in the

74 functioning and broader resilience of agricultural and natural ecosystems alike (Costanza et al.

75 1997). For US agriculture alone, insect-mediated biological control is conservatively valued at

$76 \$ 4.5-17$ billion per year, and a diverse community of natural enemies helps alleviate pressures

77 from herbivores and other crop antagonists (Losey and Vaughan, 2006). However, rapid

78 depletion of animal populations and progressive ecosystem simplification compromise the

79 strength and stability of this ecosystem service (Oliver et al., 2015; Hallmann et al., 2017). In

80 tropical terrestrial ecosystems with inherently high levels of biodiversity, these trends might be

81 even more pronounced yet routinely remain un-documented due to e.g., an overall lack of

82 sufficient funds, scientific interest and well-trained ecologists (Melo et al., 2013; Barnes et al., 83 2014).

84 Across the globe, arthropod pests reduce agricultural productivity by $10-16 \%$ and constitute

85 key impediments to food security and (indirectly) poverty alleviation (Oerke, 2006; Bebber et 86 al., 2013). Though native pests continue to pose major problems for the world's agriculture, non-

87 native species are of increasing significance as a result of trade globalization and human

88 movement (Bradshaw et al., 2016; Paini et al., 2016). Importation biological control (IBC; also

89 known as 'classical biological control'), or the judicious selection and subsequent introduction of

90 a specialized natural enemy from the pest's region of origin, has been repeatedly shown to

91 effectively reduce invasive pest populations to less damaging levels (van Driesche et al., 2008;

92 Heimpel and Mills, 2017). Particularly in the developing-world tropics, IBC can be a "silver

93 bullet" option for destructive agricultural pests, being largely self-sustaining and requiring little 
94 or no stakeholder intervention (Andrews et al., 1992). Since the late 1800s, more than 2,000

95 natural enemy species have been released against approximately 400 invasive pests worldwide,

96 occasionally resulting in complete pest control but regularly causing limited impact on target

97 pest populations (van Lenteren et al., 2006; Cock et al., 2016b). Though economic impacts are

98 not routinely assessed for IBC, levels of pest suppression and ensuing benefit:cost ratios can be

99 exceptionally favorable (5:1 to >1,000:1) (Heimpel and Mills, 2017; Gutierez et al., 1999;

100 Naranjo et al., 2015). Yet, IBC is marred with remarkably low rates of success (Greathead \&

101 Greathead, 1992; Cock et al., 2016a), and biological control as a whole is habitually undervalued

102 or even avoided while it should be promoted (Daily et al., 2009). Furthermore, over the past

103 three decades, IBC initiatives have been met with stringent regulations and a heightened

104 emphasis on potential ecological risks or unintended side-effects (Heimpel \& Cock, 2018). The

105 latter was triggered by a provocative yet necessary account by Howarth $(1983,1991)$, built

106 around misguided biological control releases that were conducted decades earlier, and in which

107 the long-established paradigm of IBC as 'ecologically-safe' practice was challenged.

108 One well-recognized IBC program is the Africa-wide initiative targeting the invasive cassava

109 mealybug, Phenacoccus manihoti (Hemiptera: Pseudococcidae), which led to a 50\% yield

110 recovery resulting in long-term economic benefits up to US \$20.2 billion as well as the likely

111 avoidance of widespread famine without negative side effects (Neuenschwander et al., 1989;

112 Herren and Neuenschwander, 1991; Zeddies et al., 2001). Key to the success of this program

113 was the carefully-selected host-specific and environmentally-adaptable parasitoid Anagyrus

114 lopezi (Hymenoptera: Encyrtidae), recovered in 1981 after foreign exploration from South

115 America, and introduced into Nigeria soon thereafter. As $A$. lopezi is considered to be a specialist

116 internal feeder on $P$. manihoti, no detrimental ecological impacts resulted from its continent- 
117 wide release (Neuenschwander, 2001). Following its devastating passage through Africa's

118 cassava belt in the 1970s and 80s, P. manihoti was inadvertently introduced into Thailand in

119 2008, spread through mainland Southeast Asia, and made its appearance in Indonesia by 2010

120 (Graziosi et al., 2016). As cassava is grown on $>4$ million ha by an estimated 8 million farming

121 families throughout tropical Asia, this pest had potential to cause massive socio-economic

122 impacts. As part of an internationally-coordinated management campaign for P. manihoti, A.

123 lopezi was promptly sourced from Benin, West Africa and 500 adult parasitoids were introduced

124 into Thailand in 2009 (Winotai et al., 2010). Parasitoids were subsequently mass-reared by

125 multiple Thai institutions, released across the country during 2010-2012 (some by airplane) and

126 introduced into neighboring Laos, Cambodia (in 2011), Vietnam (in 2013) and Indonesia (in

127 2014) (Wyckhuys et al., 2015).

128 In this study, we characterized the degree to which A. lopezi has established in the highly-

129 heterogeneous cassava cropping environments of Southeast Asia. Field research was carried out

130 over the course of 2014-2017 by various country teams, each pursuing different objectives as

131 outlined below. We employed seasonal population surveys that extended from Myanmar's

132 Ayeyawaddy River delta to the uplands of Timor in eastern Indonesia, to quantify magnitude and

133 spatial extent of parasitoid-induced P. manihoti population suppression (section i, ii).

134 Furthermore, we employed well-established manipulative protocols to assess the effectiveness of 135 A. lopezi and subsequent yield benefits of biological control (De Bach et al., 1971; van Lenteren 136 et al., 1980; Luck et al., 1988) (section iii). Finally, we conducted an analysis of production 137 statistics and cassava prices in one of Asia's main cassava-growing countries (Thailand) over a 138 time period spanning the 2008 P. manihoti invasion, the 2009 parasitoid introduction into 
139 Thailand and the subsequent (natural, and human-aided) continent-wide distribution of $A$. lopezi

140 (section iv).

141 Our work uses original datasets to present a rare, continental-scale and multi-year assessment

142 of IBC-mediated insect pest suppression, and the cascading trophic and socioeconomic effects on

143 cassava yield loss reduction and commodity prices. We combine observational and manipulative

144 studies to exemplify the benefits of $A$. lopezi as a biological control agent, and lay the basis for

145 further econometric investigations. This study illustrates the value of an insect-driven ecosystem

146 service to support agricultural sustainability, in the face of a potentially devastating invasive

147 pest.

148

149

150 Materials \& Methods

151

152

i. Multi-country pest \& natural enemy survey

153

154 From early 2014 until late 2017, insect surveys were carried out in 601 cassava fields in

155 Myanmar, Thailand, Lao PDR, Cambodia, Vietnam, southern China and Indonesia. Survey

156 protocols are described in detail in Graziosi et al. (2016). In brief, we selected older fields (i.e.,

157 8-10 months of age) in the main cassava-growing areas of each country, with individual sites

158 located at least $1 \mathrm{~km}$ apart. Five linear transects were randomly chosen per site, with ten plants

159 (routinely spaced at $0.8-1.2 \mathrm{~m}$ ) sampled in each transect. By doing so, a total of 50 plants per

160 field were assessed for P. manihoti infestation and per-plant mealybug abundance. In-field

161 identification of mealybugs was based on morphological characteristics such as coloration and 
162 presence or length of abdominal waxy filaments, while samples were also taken to the laboratory

163 for identification by specialist taxonomists. Following transect walks we calculated average $P$.

164 manihoti abundance (i.e., number of individuals per infested tip) and field-level incidence (i.e.,

165 proportion of $P$. manihoti-infested tips per field).

166 To assess local $A$. lopezi establishment and parasitism rates, we conducted dry-season sampling 167 from 2014 to 2017 at sub-sets of mealybug-invaded sites in Thailand $(n=20)$, Cambodia $(n=10$, 168 15), southern Vietnam $(n=20,20,6)$ and Indonesia $(n=10,9,21)($ total $n=131)$. Sampling 169 consisted of collecting 20 mealybug-infested tips from local fields and transferring them to a 170 laboratory to monitor subsequent parasitoid emergence (Neuenschwander et al., 1989). Surveys 171 were carried out during January-May 2014 (dry season), October-November 2014 (late rainy 172 season), January-March 2015 (dry season) in mainland Southeast Asia, and during October173 November 2014 and 2017 (dry season) in insular Indonesia. Locations were recorded using a 174 handheld GPS unit (Garmin Ltd, Olathe, KS). In-field identification of mealybugs was based on 175 morphological characters, while samples were also transferred to the laboratory for further 176 taxonomic identification. Voucher specimens of $P$. manihoti were equally deposited at the Thai 177 Department of Agriculture (Bangkok, Thailand), Bogor Agricultural University (Bogor, 178 Indonesia) and Plant Protection Research Institute (Hanoi, Vietnam).

179 To assess local $A$. lopezi establishment and parasitism rates, mealybug-infected tips were 180 collected in the field and transferred to a laboratory. Upon arrival in the laboratory, each tip was 181 carefully examined, predators were removed and the total number of $P$. manihoti was 182 determined. Tips were then placed singly into transparent polyvinyl chloride (PVC) containers, 183 closed with fine cotton fabric mesh. Over the course of three weeks, containers were inspected 184 on a daily basis for emergence of parasitoids and $A$. lopezi parasitism levels (per tip and field) 
185 were computed. Next, for fields where presence of $A$. lopezi was reported, we carried out a 186 regression analysis to relate field-level mealybug abundance with parasitism rate. Mealybug 187 infestation levels and parasitism rates were log-transformed to meet assumptions of normality 188 and homoscedasticity, and all statistical analyses were conducted using SPSS. 189

ii. Multi-year mealybug and parasitoid population assessment in Vietnam

191

192 From July 2013 until July 2015, we conducted population surveys in Tay Ninh province, 193 Vietnam; an area with near-continuous, all-year cassava cultivation (see also Le et al., 2018).

194 The cassava mealybug is assumed to have arrived in southern Vietnam during 2011-2012, and $A$. 195 lopezi was first detected from Tay Ninh province in early 2013. Eight newly-planted cassava 196 fields were selected of uniform age, crop variety, developmental stage and management. Every 197 two months, insect surveys were done within these fields to characterize P. manihoti incidence, 198 infestation pressure and A. lopezi parasitism rate. In each field, a total of five linear 10-15 m 199 transects were screened (plants routinely spaced at 0.8-1.2 m) and, 50 plants were carefully 200 inspected for P. manihoti. Phenacoccus manihoti infestation was recorded as field-level 201 abundance (number of individuals per infected tip) and field-level incidence (proportion of 202 mealybug-affected tips) at each sampling date and location. To assess A. lopezi parasitism rates, 20320 mealybug-infested tips were randomly collected from each field by breaking off the top parts 204 of individual plants, and transferred to the laboratory. Parasitism rates were estimated from these 205 samples as described above, and parasitism levels were computed for each individual field and 206 sampling date. We used analysis of variance (PROC MIXED, SAS version 9.1; SAS Institute, 207 Cary, NC) with field as the random factor, and tested the effect of cassava age, sampling date 
208 and year for P. manihoti incidence, abundance and A. lopezi parasitism. Means were compared 209 with least squares means approach. Mealybug abundance data were log-transformed while 210 incidence, parasitism and hyperparasitism data were arcsine-transformed to meet normality.

211 The intrinsic rate of mealybug population increase, $r$, over two months was calculated over 212 subsequent sampling events as $\ln \left(m_{t+1} / m_{t}\right)$ where $m=$ the per-tip mealybug density. This growth 213 rate was regressed against the mealybug parasitism rate as a means of evaluating the role of the 214 parasitoids in suppressing mealybug population growth rates and also of estimating the 215 parasitism level that correlates with a decrease in mealybug population growth rate (for other 216 uses of this approach, see Lin \& Ives 2003 and Plecas et al. 2014). The statistical significance of 217 the relationship between parasitism rate and mealybug population growth was assessed using a 218 generalized linear model incorporating normal error distribution with $r$ as the response variable 219 and parasitism level and field identity as independent variables.

220

221

iii. Exclusion cage assays

222

223 In August 2014, a field study was initiated at the Rayong Field Crops Research Center 224 (RYFCRC) in Rayong, Thailand (see Thancharoen et al., 2018). To assess the relative 225 contribution of natural enemies such as $A$. lopezi to pest control, we employed exclusion assays 226 (Snyder and Wise, 2001; Costamagna et al., 2007). More specifically, to determine separate and 227 joint effects of $P$. manihoti and $A$. lopezi on cassava crop yield, four different treatments were 228 established using two common cassava clones: Kasetsart 50 (KU50) and Rayong 72 (R72). 229 Treatments consisted of the following: 1) 'full cage' assays, in which a plant was entirely 230 covered by a mesh screen cage to exclude all natural enemies; 2) 'sham' cage assays, in which a 
231 plant was covered by a screen cage to provide a microhabitat similar to that of the 'full cage', but

232 left open at the sides to allow natural enemy access; 3) 'no cage' assays, in which a plant was

233 kept without a cage as a 'real-world' benchmark. For the 'no cage' assay, two different

234 mealybug infestation modes were adopted: (1) one single infestation with 10 mealybug adults

235 per plot at the onset of the experiment; (2) a monthly infestation with 10 P. manihoti adults per

236 plot, to ensure a sustained mealybug population over the entire course of the experiment. Each

237 treatment (i.e., a single cage containing 4 replicated plants) was established with four replicates,

238 for two different cassava clones. The experimental field was established using locally-sourced

239 stem cuttings of KU50 or R72, planted at 1-m distances within plots.

240 Once plants had reached 4.5 months of age, $2 \times 2 \times 2$ m polyvinylchloride (PVC) frame cages

241 were deployed, with four plants contained within each cage. Cages were covered with fine nylon

242 mesh screen to prevent entry by insects, including A. lopezi parasitoids. In January 2015, 10

243 adult female P. manihoti were gently brushed onto plants within each treatment. Mealybug

244 adults were obtained from a laboratory colony at RYFCRC that had been started in early 2014, in

245 which $P$. manihoti were maintained on potted cassava plants within a screen-house that were

246 regularly supplemented with field-collected individuals. Visual observations were carried out

247 within the cages on a monthly basis and P. manihoti abundance was recorded on each plant. On

248 September 7, 2015, once the crop had reached 12 months of age, cages were removed and plants

249 within the different experimental treatments were harvested manually. At harvest, fresh root

250 yield (FRY) was determined for each plant to determine treatment effects (Karlstrom et al.,

251 2016).

252 Mealybug population build-up under each experimental treatment was calculated, by

253 converting the average number of mealybugs per plant (averaged across plants within a given 
254 treatment, as to avoid pseudo-replication) on a given sampling date to cumulative mealybug-days

255 (CMD) (Ragsdale et al., 2007):

256

$257 \quad \sum_{n=1}^{\infty}=\left(\frac{x_{i}-1+x_{i}}{2}\right) \times\left(t_{i}-t_{i-1}\right)$

258

259 where $n$ is the total number of days over which sampling took place, $x_{i}$ is the number of

260 mealybugs counted on day $i$ and $t_{i}$ is the number of days since the initiation of sampling on day $i$.

261 Mealybug population build-up under each treatment was computed, and average CMD

262 measures were compared between the respective treatments using a mixed modeling approach

263 with plot as the random factor and time as the repeated measure. A mixed modeling approach

264 was used to contrast fresh root yield (FRY), using treatment and variety as fixed factors. Plant

265 survival rates were compared between treatments, using a Chi-square analysis. Where necessary,

266 data were transformed to meet assumptions of normality and homoscedasticity, and all statistical

267 analyses were conducted using SPSS. In cases where data could not be transformed to normality, 268 non-parametric tests (e.g., Kruskal-Wallis) were used.

269

270

iv. Country-wide yield changes

271

272 Crop production statistics were obtained through the Office of Agricultural Economics, Ministry 273 of Agriculture \& Cooperatives (Bangkok, Thailand). Yield measures were computed for 2006-

274 2016, for a total of 51 cassava-growing provinces within Thailand, and annual weighted means

275 were compared between successive years. Province-level yields were assigned different weights, 276 based upon the local extent of cassava cultivation (in terms of harvested area) during a given 
277 year. Cassava crop yield can be impacted by agro-climatic conditions (e.g., temperature-related 278 variables) and by attack of pests such as $P$. manihoti. To assess the impact of sustained $A$. lopezi 279 releases from the 2011 cropping season onward, mean values of yields across all the cassava280 growing provinces were regressed with explanatory variables which included rainfall, minimum 281 and maximum temperature (obtained from Thai Meteorological Department, Bangkok, 282 Thailand).. Additionally, time (year for which yield observations and agro-climatic data were 283 obtained) was also added as an explanatory variable to control for variation in the variables 284 across years. In addition, a categorical variable representing the introduction of $A$. lopezi 285 (dummy-coded as 1 for 'presence' for the 2011 and 2012 growing seasons, and dummy-coded as 2860 for 'absence' for growing seasons 2008, 2009 and 2010) was also added as an additional 287 explanatory variable in the regression model. Before proceeding for further analysis,, the 288 distribution of the response variable (i.e. yield) was tested, and was identified to be normal 289 (Shapiro test $\mathrm{p}<0.05$ ). A step-wise regression approach (forward and backward) using a linear 290 modeling approach was used to identify the model that best explains variation in yield. The 291 model with the lowest Akaike information criterion (AIC) was selected. In the next step, the 292 model with the lowest AIC score was compared with models containing interaction terms 293 between time and other explanatory variables (i.e. temperature minimum, rainfall and $A$. lopezi 294 introduction) both separately and simultaneously (see Table S1). Model with the least AIC score, 295 and the highest adjusted $\mathrm{R}^{2}$ value was selected and is described in the Results section. Regression 296 analysis was performed in R (v 3.4.1) statistical computing environment. Additionally, R 297 package "gvlma" was used to assess if the assumptions of regression were met by the selected 298 model. Additional diagnostics of the selected model, such as determination of variance inflation 299 factor (VIF) for detection of multicollinearity, the Non-constant Variance Score Test (i.e. test for 
300 heteroscedasticity of residuals over fitted values) was performed using R package "MASS" and 301 “car" respectively.

302

303

304 Results

305

306

i. Multi-country pest \& natural enemy survey

307

308 During continental-scale insect surveys from 2014 until 2017 (i.e., 5-8 years following the initial 309 A. lopezi introduction), the mealybug complex on cassava largely comprised four non-native species: (1) P. manihoti; (2) the papaya mealybug Paracoccus marginatus Williams \& Granara de Willink; (3) Pseudococcus jackbeardsleyi Gimpel \& Miller; and (4) the striped mealybug

312 Ferrisia virgata Cockerell. Phenacoccus manihoti was the most abundant and widespread 313 mealybug species, and was reported from $37.0 \%(n=549)$ and $100 \%$ fields $(n=52)$ in mainland 314 Southeast Asia and Indonesia, respectively. Among sites, $P$. manihoti reached field-level 315 incidence of $7.6 \pm 15.9 \%$ (mean \pm SD; i.e., proportion mealybug-affected tips) and abundance of $31614.4 \pm 31.0$ insects per infested tip in mealybug-affected fields (or $5.2 \pm 19.8$ insects per tip 317 across all fields) in mainland Southeast Asia, and incidence rates of $52.7 \pm 30.9 \%$ and $42.5 \pm$ 31867.7 individuals per tip in Indonesia. Field-level incidence and population abundance were 319 highly variable among settings and countries, reaching respective maxima of $100 \%$, and 412.0 320 individuals per tip (Fig. 1).

321 When examining P. manihoti parasitism rates from a select set of sites, A. lopezi was present 322 in $96.9 \%$ of mealybug-affected fields $(n=97)$ in mainland Southeast Asia, yet were only found in 
$32327.5 \%$ sites $(n=40)$ across Indonesia. Among sites, highly variable parasitism rates were evident

324 with dry-season rates of $16.3 \pm 3.4 \%$ in coastal Vietnam, versus $52.9 \pm 4.3 \%$ in intensified

325 systems of Tay Ninh (also in Vietnam). In Indonesia, A. lopezi was found in $22.0 \%$ fields in

326 Lombok $(n=9)$ and was absent from prime growing areas in Nusa Tenggara Timur (NTT). In

327 sites where $A$. lopezi had successfully established, dry-season parasitism ranged from $0 \%$ to

$32897.4 \%$, averaging $30.0 \pm 24.0 \%(n=110)$ (Fig. S1). In fields where A. lopezi had effectively

329 established, mealybug pest pressure exhibited a negative regression with parasitism rate $\left(\mathrm{F}_{1,98}=\right.$

$\left.33013.162, \mathrm{p}<0.001 ; \mathrm{R}^{2}=0.118\right)$.

331

332

ii. Multi-year mealybug and parasitoid population assessment in Vietnam

333

334 Over the course of three years, we monitored P. manihoti abundance, field-level incidence and

335 associated $A$. lopezi parasitism rates in Tay Ninh, southern Vietnam. Field-level incidence of $P$.

336 manihoti ranged from $0 \%$ to $82 \%$, averaging $24.8 \pm 17.7 \%$ (mean $\pm \mathrm{SD}$ ) plants infested over two

337 consecutive crop cycles. Mealybug incidence was significantly higher on older crops $\left(\mathrm{F}_{7,57}=9.9\right.$;

$338 \mathrm{p}<0.0001$ ), and rapidly increased during the dry season. Similarly, mealybug abundance (average

$3395.6 \pm 5.0$ individuals per tip) was higher during the dry season $\left(\mathrm{F}_{1,63}=9.10 ; \mathrm{P}=0.0037\right)$, and in

340 crops older than six months, when compared to younger crops $\left(\mathrm{F}_{7,57}=2694.06 ; \mathrm{P}<0.0001\right)$.

341 From mid-2014 onward, mealybug populations remained at field-level abundance below 10-15

342 individuals per infested tip (Fig. 2). Furthermore, A. lopezi attained mean parasitism rates of 42.3

$343 \pm 21.7 \%$, with maxima of $76.7 \pm 28.9 \%$ during the early rainy season (Fig. 2 ). Overall,

344 parasitism gradually increased over the dry season, up until crops were 4-6 months old. 
345 Mealybug growth rates were significantly and negatively correlated with parasitism levels

346 across the 8 sites studied (GLM w/ Normal error distribution and corrected for field: $\chi^{2}{ }_{1}=125.4$;

$347 P=0.0017$; the field term was not significant; $\chi^{2}{ }_{7}=0.2 ; P=1$ ) (Fig. 3). The $\mathrm{x}$-intercept of each

348 per-field regression represents the parasitism level above which mealybug growth rates are

349 negative and this value ranged between 0.38 and 0.69 for the 8 sites (average $=0.47 \pm 0.09$ ) (Fig.

3503 ). Whilst $A$. lopezi was the sole primary parasitoid at this location, three hyperparasitoid species

351 attacked it at $2.79 \pm 5.38 \%$ levels (as \% of parasitized hosts).

352

353

iii. Exclusion cage assays

354

355 Over the entire assay, $P$. manihoti populations under 'full cage' attained 48,318 $\pm 51,425(n=4$;

356 mean \pm SD) and 7,256 $\pm 8,581$ cumulative mealybug days (CMD) in 'sham cage' for one 357 popular variety (i.e., R72) (Thancharoen et al., 2018; Fig. 4). For a second variety, KU50, $P$.

358 manihoti attained 28,125 $\pm 32,456 \mathrm{CMD}$ in a 'full cage' treatment, and 1,782 $\pm 1,073 \mathrm{CMD}$ in

359 'sham cage'. This compared to CMD measures in a 'no cage' control of 1,378 $\pm 1,039$ and $342 \pm$ 360 252, for R72 and KU50 respectively. CMD measures were significantly affected by treatment $361 \quad\left(\mathrm{~F}_{3,189}=240.752, \mathrm{p}<0.001\right)$ and time $\left(\mathrm{F}_{6,189}=113.347, \mathrm{p}<0.001\right)$, and the interaction term time $\mathrm{x}$ 362 treatment $\left(\mathrm{F}_{18,189}=2.012, \mathrm{p}=0.011\right)$. Also, total $\mathrm{CMD}$ measures at the end of the trial 363 significantly differed between treatments for both R72 and KU $50\left(F_{3,12}=6.767, p=0.006 ; F_{3,12}=\right.$ $36411.152, \mathrm{p}=0.001$, respectively).

365 Cassava yield parameters varied considerably under the four experimental treatments, and for 366 both crop varieties (see Thancharoen et al., 2018). For Rayong 72, plant survival attained $37.5 \%$ 367 under 'full cage' as compared to $75 \%$ and $87.5 \%$ under 'no cage' or 'sham cage' conditions, 
368 respectively (Chi square, $\chi^{2}=10.473, p=0.015$ ). Fresh root yield (FRY) was significantly

369 affected by treatment $\left(\mathrm{F}_{3,27}=4.104, \mathrm{p}=0.016\right)$ and variety $\left(\mathrm{F}_{1,27}=4.364, \mathrm{p}=0.046\right)$. For $\mathrm{R} 72$ and

370 KU50, FRY under 'full cage' was $74.6 \%$ or $71.2 \%$ lower than under 'sham cage' (Kruskal-

371 Wallis, $\chi^{2}=8.344, \mathrm{p}=0.039 ; \chi^{2}=19.134, \mathrm{p}<0.001$, respectively), and respective yield reductions

372 for both varieties were $77.2 \%$ and $67.8 \%$ compared to 'no cage' treatments.

373

374 iv. Country-wide yield changes

375

376 During the 2009 dry season, $P$. manihoti attained its peak population in Thailand, with field-level

377 incidence near $100 \%$ and abundance rates of hundreds of $P$. manihoti per plant on at least

378 230,000 ha (Rojanaridpiched et al. 2013). Over the subsequent 2009-10 cropping season,

379 province-level crop yields dropped by $12.59 \pm 9.78 \%$ nationwide (weighted mean: $-18.2 \%$ ) (Fig.

380 5). Furthermore, country-wide aggregate yields declined from $22.67 \mathrm{t} / \mathrm{ha}$ to $18.57 \mathrm{t} / \mathrm{ha}$, and total

381 production dropped by $26.86 \%$ to $22,005,740$ tonnes of fresh root. Following the lowered crop

382 output, prices for Thai cassava starch increased 2.38-fold at domestic prices in Thailand, and

383 2.62-fold at export prices (US\$ FOB, Free On Board) (Fig. S2). However, in the following

384 growing seasons (i.e., 2011 and 2012), there was a marked improvement in yield across all

385 regions, as compared to previous years (Fig. 5). It was also from mid-2010 onward that country-

386 wide mass releases of $A$. lopezi were carried out. To test if the $A$. lopezi introduction was

387 responsible for this improvement in yield, and to differentiate $P$. manihoti-induced yield drops

388 from agro-climatic climatic impacts and changes across years, regression analyses were carried

389 out with yield as response variable and agro-climatic parameters, year ("time"), and $A$. lopezi

390 presence as explanatory variables. Multiple regression analysis revealed that a model with 
391 interaction terms between time and all explanatory variables, i.e. time of introduction of $A$. lopezi

392 and rainfall had the lowest AIC score and the higest explanatory power (adjusted $\mathrm{R}^{2}$ ) (Table S1).

393 The model showed a significantly positive effect $\left(\mathrm{F}_{7,183}=8.641\right)$ of the interaction term Time $\mathrm{x}$

394 Presence (i.e., 'presence' of $A$. lopezi and time, $\mathrm{p}<0.01$ ) on observed yields. The best model

395 indicated that the introduction of $A$. lopezi (and not agro-climatic variables or changes in those

396 variables over time) significantly increased yields across all cassava-growing regions during the

3972011 and 2012 cropping seasons.

398

399

400 Discussion

401

402

In 2008, the invasive mealybug P. manihoti accidentally arrived in Thailand. Through its

403 extensive spatial spread, rapid population build-up and unrestricted feeding on plants (this lead to 404 stunting and plant death), P. manihoti caused significant yield declines and a 27\% drop in the 405 nation's cassava production. This study shows how the neotropical parasitoid, A. lopezi, released 406 throughout Thailand for mealybug control in 2010, had effectively established in 97\% mealybug407 affected fields in mainland Southeast Asia by 2014, and colonized 27\% sites across insular 408 Indonesia by late 2017. Attaining average dry-season parasitism rates of $30 \%$ across sites, $A$. 409 lopezi populations readily oscillate with those of its mealybug host and suppress $P$. manihoti to 410 incidence levels of $7 \%$ and background infestation pressure of a mere 14 individuals per 411 (infested) tip. Experimental assays using two widely-grown cassava varieties reveal how 412 biological control secures approximate yield gains of 5.3-10.0 t/ha. Our work clearly 413 demonstrates how $A$. lopezi downgrades the invasive $P$. manihoti to non-economic levels at a 
414 continental scale, without any known detrimental side-effects. Offering a quantitative assessment

415 of IBC's contribution to (the restoration of) primary productivity in Asia's cassava crop, our

416 work illuminates the broader societal value of biological control in a geographical region where

417 there is heavy and increasing use of pesticides (Schreinemachers et al., 2015).

418 Aside from featuring as a 'beacon of hope' in Asia's pesticide-tainted farming systems, our

419 work heralds a new era for the discipline of insect biological control. Since the late 1800s,

420 biological control has permitted the complete or partial suppression of 226 debilitating insect

421 pests globally, it has formed the crux of founding ecological theories (e.g., Hairston et al., 1960),

422 and was widely deemed to be a safe, dependable and preferred means for (invasive) pest control

423 for most of its history. Following the release of Rachel Carson's 1962 Silent Spring, biological

424 control was met with unrestrained enthusiasm and a firm belief in its potential as a dependable

425 alternative to pesticide-centered practices. Yet, as concerns over its ecological risks rose

426 following Howarth's $(1983,1991)$ denunciation of few historic cases of malpractice, regulatory

427 hurdles surfaced, public funding lowered and the practice of insect biological control went

428 through trying yet necessary reform (Strong \& Pemberton, 2000; Hoddle, 2004; Messing \&

429 Brodeur, 2018). Over the past three decades, IBC implementation has centered on ecological

430 safety and increasingly strives to balance environmental benefits and risks (Heimpel \& Cock,

431 2018). Though weed biological control indeed has a 99\% safety record (Suckling \& Sforza,

432 2014), scientists are conscious that ecological risk will never be zero and that certain risk factors

433 are difficult to anticipate and predict (Crooks \& Soule, 1999; Sexton et al., 2017). In the

434 meantime, it's well-recognized that invasive pests tend to present far higher threats to native

435 biota than judiciously-selected natural enemies with a narrow dietary breadth (Culliney, 2005).

436 Though the 1980s Africa campaign against $P$. manihoti was implemented during times when the 
437 primary focus of insect biological control was on benefits (but see Neuenschwander, 2001), risks 438 were considered to be minimal and did not delay implementation. The fact that $A$. lopezi was 439 both effective and highly host-specific vindicated this. As a result, the implementation of IBC in 440 Southeast Asia more than 30 years later was greatly facilitated by recognizing that $(i)$ IBC had 441 been effective across Africa's cassava-belt, and ( $i i)$ widespread benefits were amplified because 442 of an absence of negative environmental side-effects on non-target species.

443 In light of the above, $A$. lopezi attained consistently high parasitism rates across most of the $P$. 444 manihoti range of climatic suitability in tropical Asia (Yonow and Kriticos, 2017), except for 445 insular Indonesia where it was only introduced at one site in late 2014. The far superior $P$. 446 manihoti infestation pressure in eastern Indonesia (i.e., NTT, Lombok), where $A$. lopezi waits to 447 be introduced, further emphasize the contribution of this parasitoid to mealybug control. Across 448 locations, A. lopezi attained maximum parasitism levels of 98\% (in late dry season, at Tay Ninh), 449 which greatly surpassed the 33-36\% established threshold (of maximum parasitism rate) for 450 successful biological control - i.e., which results in lasting pest population suppression (Hawkins 451 and Cornell, 1994). At multiple sites, parasitism rates equally surpassed (max. 30\%) levels from 452 smallholder plots in Africa's savanna (Hammond and Neuenschwander, 1990). Factors ensuring 453 this exceptional parasitoid efficacy and resulting pest control are a) unique features of the 454 cassava crop, including prolonged durational stability, vegetational complexity and a constitutive 455 secretion of energy-rich nectar for foraging parasitoids (Pinto-Zevallos et al., 2016); b) spatio456 temporal continuity of mealybug-infested crops at a landscape level (Schellhorn et al., 2014), 457 especially in locations where farmers employ staggered planting and piece-meal harvesting; c) 458 favorable ecological traits of $A$. lopezi, including high dispersal ability, environmental 459 adaptability and density-dependent parasitism (Neuenschwander et al., 1989); d) non- or limited 
460 use of (prophylactic) insecticides, except for Thailand and parts of southern Vietnam; and e)

461 human-assisted dispersal of $A$. lopezi, via (parasitized) mealybug-infested planting material

462 (Herren et al., 1987). Furthermore, substantial fertilizer inputs and suitable water management in 463 areas with intensified cassava production -e.g., Vietnam's Tay Ninh province, or parts of eastern 464 Thailand such as Nakhon Ratchassima- likely benefited biological control further by boosting $A$. 465 lopezi development and fitness (Wyckhuys et al., 2017a). All of the above factors may have 466 contributed to the stabilization of mealybug populations at $25 \%$ incidence and field-level 467 abundance below 10-15 individuals per infested tip, similar to what was observed in Africa 468 during the 1980s campaign (Fig 2; Hammond and Neuenschwander, 1990).

469 Exclusion cage assays illustrated how biological control enabled a root yield recovery of 5.3$47010.0 \mathrm{t} / \mathrm{ha}$ in two main cassava varieties, and how 2015 yields under 'no cage' (i.e., 'real-world') 471 conditions were in line with historic in-country yield tendencies. Though no direct field-level 472 measurements were made of $A$. lopezi parasitism during the cage trials, biological control was 473 found to occupy a central role in lowering P. manihoti populations (Thancharoen et al., 2018), 474 and A. lopezi is a determining factor in ensuring mealybug suppression in other key cassava475 growing areas in Southeast Asia (Le et al., 2018). Cage trials also showed large variability in 476 responses between the two cassava clones, likely reflective of differences in plant vigor and an 477 individual clone's photosynthetic capability (Connor et al., 1981; Cock et al., 2012). The cassava 478 plant does possess a unique set of features to sustain root production under (a)biotic stress, 479 including the adaptive mobilization of biomass and a highly-effective use of resources (Cock et 480 al. 2012). Yet, the pronounced production losses - under cage conditions, especially for R72 481 can be ascribed to continuous (unrestrained) attack of the active apex, direct damage to stems 482 and high rates of plant death. 
483

484

485

486

487

488

489

490

491

492

493

494

495

496

497

498

499

500

501

502

503

504

505

As $P$. manihoti currently occurs at low infestation pressure across mainland Southeast Asia, cage assays lend themselves to further extrapolation to a broader geographical scale. Yet, local environmental conditions may still affect parasitoid abundance, efficacy and (biological control) impact. For example, slightly higher $P$. manihoti population levels were recorded in settings with sandy, low-fertile soils (Wyckhuys et al., 2017a) and biological control under those conditions merits closer research attention. Also, as landscape composition and plant disease infection status equally modulate $P$. manihoti performance and efficacy of biological control at local scale (Wyckhuys et al., 2017b; Le et al., 2018), further replicated trials could be warranted to validate the robustness of our findings under varying agro-ecological contexts. Despite the above confounding factors, careful analysis of production statistics and commodity market fluxes (as in section $i v$ ) support our empirical results and confirm $A$. lopezi to be the major biotic factor affecting mealybug population growth. In the meantime, Indonesian sites where $A$. lopezi has not yet established now constitute a 'natural laboratory' to refine and validate existing projections on A. lopezi-mediated yield gain (and crop recovery), in advance of the natural arrival / introduction of the parasitoid.

In tropical Asia, cassava underpins a multi-billion dollar starch sector, constitutes a key source of farm income and provides an (oftentimes indirect) means to food security for poor, underprivileged populations (Howeler, 2014; Delaquis et al., 2017). On the one hand, the P. manihotiinduced yield shocks, as recorded during 2009-2011, can have major implications for rural livelihoods. Sustained pest attack can aggravate food security issues in areas where cassava is a prime food staple or progress into chronic 'poverty traps' (Tittonell et al., 2013), all of which is counteracted through $A$. lopezi-mediated biological control. Aside from restoring FRY, A. lopezi equally helped recover a plant's total dry matter or 'biological yield' (Thancharoen et al., 2018), 
506 which is particularly relevant in various parts of tropical Asia where cassava leaves and shoots

507 constitute part of the local diet of rural communities. On the other hand, the net productivity loss

508 of 5.14 million ton of fresh root equaled a respective loss of revenue of US\$267.5-591.7 million

509 (at 2009-10 factory price) for Thailand's cassava sector and the Asia-based starch industry.

510 Hence, aside from its manifest (direct, indirect) contribution to local food security, socio-

511 economic benefits of the $P$. manihoti campaign are deemed to be substantial and potentially

512 equal or even surpass those recorded previously in Africa (Zeddies et al., 2001).

513 Yield recovery levels in our cage assays were considerably higher than the $2.5 \mathrm{t} /$ ha yield

514 increase recorded through on-farm measurements in sub-Saharan Africa (Neuenschwander et al.,

515 1989). At Thai farm-gate prices, A. lopezi-mediated yield recovery equals to US\$200-704 per ha

516 (Thancharoen et al., 2018), though this does not take into account changes in production costs,

517 local elasticities of supply and demand, or (often substantial) insecticide / fertilizer expenditures.

518 Though we do call for caution in extrapolating our findings, the approximate value of $P$.

519 manihoti biological control in Asia could thus be hundreds of dollars higher than existing

520 estimates of $\$ 63$ ha $^{-1}$ year-1 across global biomes including natural systems (Costanza et al.

521 1997), $\$ 33$ ha $^{-1}$ year $^{-1}$ for (natural) biological control of the soybean aphid in the US Midwest

522 (Landis et al., 2008), or $\$ 75$ to $\$ 310$ ha $^{-1} \mathrm{year}^{-1}$ for bird-mediated pest control in Costa Rican

523 coffee (Karp et al., 2013). From the above it can equally be deduced that the potential of insect

524 biological control has been significantly under-valued (Landis et al., 2008; Naranjo et al., 2015),

525 and that comprehensive cost-benefit analyses are urgently needed to raise (or restore) societal

526 recognition of this important and safe ecosystem service.

527 These substantial economic benefits of (naturally-occurring, cost-free) biological control need

528 to be contrasted with the unrelenting global increase in the use of insecticides for the mitigation 
529 of (domestic and, increasingly invasive) pests (Enserink et al., 2013). Following the P. manihoti

530 invasion, pesticides have equally become pervasive in Thailand's cassava crop and growers have

531 embraced the (prophylactic) use of neonicotinoid insecticides. Yet, given the omnipresence of $A$.

532 lopezi and the largely low mealybug population levels in pesticide-free cassava plots across

533 Southeast Asia, cost-effectiveness of such approaches needs closer scrutiny. Though pesticides

534 do bring certain benefits to society, they tend to simplify ecological communities, adversely

535 impact natural enemies and thus accelerate pest proliferation (Lundgren and Fausti, 2015). On

536 the other hand, our work shows how a carefully-selected, specialist natural enemy constitutes a

537 viable alternative to insecticide-centered approaches. Hence, potential (non-target ecological)

538 risks of classical biological control have to be viewed in terms of refraining from action and thus

539 creating room for far-less environmentally-friendly tactics such as (systemic) pesticides

540 (Messing and Wright, 2006; Suckling and Sforza, 2014; Hajek et al., 2016).

541

542

\section{Conclusions}

544

545 This study provides a quantitative assessment of how importation biological control (IBC)

546 helped restore primary productivity in Asia's cassava crop, following the arrival and extensive

547 spread of an invasive sap-feeding pest, i.e., the cassava mealybug. We demonstrate that IBC can

548 provide durable and cost-effective control of the invasive $P$. manihoti, and delivers substantial

549 and sustainable socio-economic and environmental benefits (Bale et al., 2008; Naranjo et al.,

550 2015). Furthermore, we emphasize that by recognizing the minimal ecological risks associated

551 with the introduction of a highly host-specific parasitoid and by deliberately balancing benefits 
552 and risks of biological control (see Heimpel \& Cock, 2018), the transformative potential of IBC

553 can be fully exploited. In a world typified by massive declines in insect numbers, extreme

554 biodiversity loss, and dwindling public interest in biological control (Bale et al., 2008; Hallmann

555 et al., 2017; Warner et al., 2012), our research underlines the immense yet largely untapped

556 potential of ecologically-based approaches to resolve (invasive) pest problems. We advocate that

557 (judiciously-implemented) IBC can positively assist with intensifying global agriculture and help 558 feed a growing world population in the 21 st century.

559

560 Acknowledgements

561

562 This manuscript presents original data-sets, generated through fully collaborative research, with 563 trials jointly conceptualized, defined and executed by national program staff and CIAT 564 personnel. This paper is dedicated to the memory of Drs. R.J. O'Neil and A.C. Bellotti 565 pioneers in the field of insect biological control.

566

567

568

569 
570

571

572

573

574

575

576

577

578

579

580

581

582

583

584

585

586

587

588

589

590

591

592

593

594

595

596

597

598

599

600

601

602

603

604

605

606

607

608

\section{References}

Andrews KL, Bentley JW \& Cave RD (1992) Enhancing biological control's contributions to integrated pest management through appropriate levels of farmer participation. Florida Entomologist, 75, 429-439.

Bale JS, van Lenteren JC \& Bigler F (2008) Biological control and sustainable food production. Philosophical Transactions of the Royal Society of London B, 363, 761-776.

Barnes AD, Jochum M, Mumme S, Haneda NF, Farajallah A, Widarto TH \& Brose U (2014) Consequences of tropical land use for multitrophic biodiversity and ecosystem functioning. Nature Communications, 5, 5351.

Bebber DP, Ramotowski MAT \& Gurr SJ (2013) Crop pests and pathogens move polewards in a warming world. Nature Climate Change, 3, 985-988.

Bradshaw CJ, Leroy B, Bellard C, Roiz D, Albert C, Fournier A, Barbet-Massin M, Salles JM, Simard F \& Courchamp F (2016) Massive yet grossly underestimated global costs of invasive insects. Nature Communications, 7, 12986.

Cock JH (2012) Cassava growth and development. In: Howeler RH (Ed.), The cassava handbook: a reference manual, pp. 39-61. International Center for Tropical Agriculture CIAT, Cali (Colombia).

Connor DJ, Cock JH, Parra GE (1981) Response of cassava to water shortage. I. Growth and yield. Field Crops Research 4: 181-200.

Cock MJW, Day RK, Hinz HL, Pollard KM, Thomas SE, Williams FE, Witt ABR \& Shaw RH (2016a) The impacts of some classical biological control successes. CAB Reviews, 10(42), 58 pp.

Cock MJ, Murphy ST, Kairo MT, Thompson E, Murphy RJ \& Francis AW (2016b) Trends in the classical biological control of insect pests by insects: an update of the BIOCAT database. BioControl, 61, 349-363.

Costanza R, d'Arge R, De Groot R, Farber S, Grasso M, Hannon B, Limburg K, Naeem S, O'Neill RV, Paruelo J \& Raskin RG (1997) The value of the world's ecosystem services and natural capital. Nature, 387, 253-260.

Costamagna AC, Landis DA \& DiFonzo CD (2007) Suppression of soybean aphid by generalist predators results in a trophic cascade in soybeans. Ecological Applications, 17, 441-451.

Crooks JA \& Soulé ME (1999). Lag times in population explosions of invasive species: causes and implications. In Sandlund, Schei, Viken (eds.): Invasive Species and Biodiversity Management, pp. 103-125.

Culliney TW (2005) Benefits of classical biological control for managing invasive plants. Critical Reviews in Plant Sciences, 24, 131-150.

Daily GC, Polasky S, Goldstein J, Kareiva PM, Mooney HA, Pejchar L, Ricketts TH, Salzman J \& Shallenberger R (2009) Ecosystem services in decision making: time to deliver. Frontiers in Ecology and the Environment, 7, 21-28. 
609 DeBach P \& Huffaker CB (1971) Experimental techniques for evaluation of the effectiveness of 610 natural enemies. In: Huffaker CB (Ed.) Biological Control. Springer, Boston, MA, pp. 113611140.

612 Delaquis E, de Haan S \& Wyckhuys KAG (2017) On-farm diversity offsets environmental 613 pressures in tropical agro-ecosystems: a synthetic review for cassava-based systems.

614 Agriculture, Ecosystems and Environment, 251, 226-235.

615 Enserink M, Hines PJ, Vignieri SN, Wigginton NS \& Yeston JS (2013) The pesticide paradox. 616 Science, 341, 728-729.

617 Gardiner MM, Landis, DA, Gratton, C, DiFonzo, CD, O’Neal, M Chacon JM, Wayo MT, 618 Schmidt NP, Mueller EE \& Heimpel GE (2009) Landscape diversity enhances biological 619 control of an introduced crop pest in the north-central USA. Ecological Applications, 19, 143620154.

621 Graziosi I, Minato N, Alvarez E, Ngo DT, Hoat TX, Aye TM, Pardo JM, Wongtiem P \& 622 Wyckhuys KAG (2016) Emerging pests and diseases of South-east Asian cassava: a 623 comprehensive evaluation of geographic priorities, management options and research needs.

624 Pest Management Science, 72, 1071-1089.

625 Greathead DJ \& Greathead AH (1992) Biological control of insect pests by insect parasitoids and 626 predators: the BIOCAT database. Biocontrol News and Information, 13, 61N-68N.

627 Gutierez AP, Caltagirone LE \& Meikle W (1999) Evaluation of results. Economics of biological 628 control. In: Bellows TS \& Fisher TW (Eds.) Handbook of biological control. Academic Press, 629 San Diego, CA, USA, pp. 243-252.

630 Hairston NG, Smith FE, Slobodkin LB (1960). Community structure, population control and 631 competition. American Naturalist, 94, 421-425.

632 Hajek AE, Hurley BP, Kenis M, Garnas JR, Bush SJ, Wingfield MJ, Van Lenteren JC \& Cock

633 MJ (2016) Exotic biological control agents: a solution or contribution to arthropod invasions.

634 Biological Invasions, 18, 953-969.

635 Hallmann CA, Sorg M, Jongejans E, Siepel H, Hofland N, Schwan H, Stenmans W, Müller A, 636 Sumser H, Hörren T \& Goulson D (2017) More than 75 percent decline over 27 years in total 637 flying insect biomass in protected areas. PLOS ONE, 12, e0185809.

638 Hammond WNO \& Neuenschwander P (1990) Sustained biological control of the cassava 639 mealybug Phenacoccus manihoti (Homoptera: Pseudococcidae) by Epidinocarsis lopezi 640 (Hymenoptera: Encyrtidae) in Nigeria. Entomophaga, 35, 515-526.

641 Hawkins BA \& Cornell HV (1994) Maximum parasitism rates and successful biological control.

642 Science, 266, 1886.

643 Heimpel GE \& Mills NJ (2017) Biological control: ecology and applications. Cambridge 644 University Press, Cambridge UK, 386 p.

645 Heimpel GE \& Cock MJW (2018) Shifting paradigms in the history of classical biological 646 control. BioControl, 63, 27-37.

647 Herren HR \& Neuenschwander P (1991) Biological control of cassava pests in Africa. Annual 648 Review of Entomology, 36, 257-283. 
649 Herren HR, Neuenschwander P, Hennessey RD \& Hammond WNO (1987) Introduction and

650

651

652

653

654

655

656

657

658

659

660

661

662

663

664

665

666

667

668

669

670

671

672

673

674

675

676

677

678

679

680

681

682

683

684

685

686

dispersal of Epidinocarsis lopezi (Hym., Encyrtidae), an exotic parasitoid of the cassava mealybug, Phenacoccus manihoti (Hom., Pseudococcidae), in Africa. Agriculture, Ecosystems \& Environment, 19, 131-144.

Hoddle MS (2004) Restoring balance: using exotic species to control invasive exotic species. Conservation Biology, 18, 38-49.

Howarth FG (1983) Classical biological control: panacea or Pandora's Box? Proceedings of the Hawaiian Entomological Society, 24, 239-244.

Howarth FG (1991) Environmental impacts of classical biological control. Annual Review of Entomology, 36, 485-509.

Howeler R (2014) Sustainable soil and crop management of cassava in Asia. International Center for Tropical Agriculture, CIAT. Cali, Colombia, $280 \mathrm{p}$.

Karlström A, Calle F, Salazar S, Morante N, Dufour D \& Ceballos H (2016) Biological implications in cassava for the production of amylose-free starch: Impact on root yield and related traits. Frontiers in Plant Science, 7, 604.

Karp DS, Mendenhall CD, Sandí RF, Chaumont N, Ehrlich PR, Hadly EA \& Daily GC (2013) Forest bolsters bird abundance, pest control and coffee yield. Ecology Letters, 16, 1339-1347. Landis DA, Gardiner MM, van der Werf W \& Swinton SM (2008) Increasing corn for biofuel production reduces biocontrol services in agricultural landscapes. Proceedings of the National Academy of Sciences USA, 105, 20552-20557.

Le TTN, Graziosi I, Cira TM, Gates MW, Wyckhuys KAG (2018) Landscape context does not constrain biological control of Phenacoccus manihoti in intensified cassava systems of southern Vietnam. Biological Control, 121, 129-139..

Lin LA \& Ives AR (2003) The effect of parasitoid host-size preference on host population growth rates: an example of Aphidius colemani and Aphis glycines. Ecological Entomology, 28, 542-550.

Losey J \& Vaughan M (2006) The economic value of ecological services provided by insects. BioScience, 56, 311-323.

Luck RF, Shepard BM \& Kenmore PE (1988) Experimental methods evaluating arthropod natural enemies. Annual Review of Entomology, 33, 367-391.

Lundgren JG \& Fausti SW (2015) Trading biodiversity for pest problems. Science Advances, 1, e1500558.

Melo FP, Arroyo-Rodríguez V, Fahrig L, Martínez-Ramos M \& Tabarelli M (2013) On the hope for biodiversity-friendly tropical landscapes. Trends in Ecology and Evolution, 28, 462-468.

Messing RH \& Wright MG (2006) Biological control of invasive species: solution or pollution? Frontiers in Ecology and the Environment, 4, 132-140.

Messing RH \& Brodeur J (2018) Current challenges to the implementation of classical biological control. BioControl, 63, 1-9. 
687 Naranjo SE, Ellsworth PC \& Frisvold GB (2015) Economic value of biological control in integrated pest management of managed plant systems. Annual Review of Entomology, 60, 1-

689 25 .

690

Neuenschwander P (2001) Biological control of the cassava mealybug in Africa: a review.

691 Biological Control, 21, 214-229.

692 Neuenschwander P, Hammond WO, Gutierrez AP, Cudjoe AR, Adjakloe R, Baumgärtner JU \&

693

694

695

696

697

698

699

700

701

702

703

704

705

706

707

708

709

710

711

712

713

714

715

716

717

718

719

720

721

722

723

724

725

Regev U (1989) Impact assessment of the biological control of the cassava mealybug, Phenacoccus manihoti Matile Ferrero (Hemiptera: Pseudococcidae) by the introduced parasitoid Epidinocarsis lopezi (De Santis) (Hymenoptera: Encyrtidae). Bulletin of Entomological Research, 79, 579-594.

Oerke EC (2006) Crop losses to pests. The Journal of Agricultural Science, 144, 31-43.

Oliver TH, Isaac NJ, August TA, Woodcock BA, Roy DB \& Bullock JM (2015) Declining resilience of ecosystem functions under biodiversity loss. Nature Communications, 6, 10122.

Paini DR, Sheppard AW, Cook DC, De Barro PJ, Worner SP \& Thomas MB (2016) Global threat to agriculture from invasive species. Proceedings of the National Academy of Sciences USA, 113, 7575-7579.

Pinto-Zevallos DM, Pareja M \& Ambrogi BG (2016) Current knowledge and future research perspectives on cassava (Manihot esculenta Crantz) chemical defenses: an agro-ecological view. Phytochemistry, 130, 10-21.

Plecas M, Gagic V, Jankovic M, Petrovic-Obradovic O, Kavallieratos NG, Tomanovic Z, Thies C, Tscharntke T \& Cetkovic A (2014) Landscape composition and configuration influence cereal aphid-parasitoid-hyperparasitoid interactions and biological control differentially across years. Agriculture Ecosystems \& Environment, 183, 1-10.

Ragsdale DW, McCornack BP, Venette RC, Potter BD, MacRae IV, Hodgson EW, O'Neal ME, Johnson KD, O'Neil RJ, DiFonzo CD \& Hunt TE (2007) Economic threshold for soybean aphid (Hemiptera: Aphididae). Journal of Economic Entomology, 100, 1258-1267.

Rojanaridpiched C, Thongnak N, Jeerapong L \& Winotai A (2013) Rapid response to the accidental introduction of the mealybug, Phenacoccus manihoti. In: Anonymous (ed) "Save and Grow": Cassava. A guide to sustainable production intensification. Food and Agriculture Organization of the United Nations, FAO, Rome, pp. 81-82.

Schellhorn NA, Bianchi FJJA \& Hsu CL (2014) Movement of entomophagous arthropods in agricultural landscapes: links to pest suppression. Annual Review of Entomology, 59, 559-581. Schreinemachers P, Afari-Sefa V, Heng CH, Dung PTM, Praneetvatakul S \& Srinivasan R (2015) Safe and sustainable crop protection in Southeast Asia: status, challenges and policy options. Environmental Science \& Policy, 54, 357-366.

Sexton JP, Montiel J, Shay JE, Stephens MR \& Slatyer RA (2017). Evolution of ecological niche breadth. Annual Review of Ecology, Evolution, and Systematics, 48, 183-206.

Snyder WE \& Wise DH (2001) Contrasting trophic cascades generated by a community of generalist predators. Ecology, 82, 1571-1583. 
726

727

728

729

730

731

732

733

734

735

736

737

738

739

740

741

742

743

744

745

746

747

748

749

750

751

752

753

754

755

756

757

758

759

760

761

Strong DR \& Pemberton RW (2000) Biological control of invading species - risk and reform.

Science, 288, 1969-1970.

Suckling DM \& Sforza RFH (2014) What magnitude are observed non-target impacts from weed biocontrol? PLoS ONE, 9, e84847.

Thancharoen A, Lankaew S, Moonjuntha P, Wongphanuwat T, Sangtongpraow B, Ngoenklan R, Kittipadakul P \& Wyckhuys KAG (2018) Effective biological control of an invasive mealybug pest enhances root yield in cassava. Journal of Pest Science, Online Early.

Tittonell P \& Giller KE (2013) When yield gaps are poverty traps: The paradigm of ecological intensification in African smallholder agriculture. Field Crops Research, 143, 76-90.

van Driesche R, Hoddle M \& Center T (2008) Control of pests and weeds by natural enemies. Blackwell Publishing Limited, Malden, MA, USA, 484 p.

van Lenteren JC (1980) Evaluation of control capabilities of natural enemies: does art have to become science? Netherlands Journal of Zoology, 30, 369-381.

Van Lenteren JC, Bale J, Bigler F, Hokkanen HMT \& Loomans AJM (2006) Assessing risks of releasing exotic biological control agents of arthropod pests. Annual Review of Entomology, 51, 609-634.

Warner KD, Daane KM, Getz CM, Maurano SP, Calderon S \& Powers KA (2011) The decline of public interest agricultural science and the dubious future of crop biological control in California. Agriculture and Human Values, 28, 483-496.

Winotai A, Goergen G, Tamò M \& Neuenschwander P (2010) Cassava mealybug has reached Asia. Biocontrol News and Information, 31, 10N-11N.

Wyckhuys KAG, Burra DD, Tran DH, Graziosi I, Walter AJ, Nguyen TG, Trong HN, Le BV, Le TTN \& Fonte SJ (2017a) Soil fertility regulates invasive herbivore performance and top-down control in tropical agro-ecosystems of Southeast Asia. Agriculture, Ecosystems and Environment, 249, 38-49.

Wyckhuys KAG, Graziosi I, Burra DD \& Walter AJ (2017b) Phytoplasma infection of a tropical root crop triggers bottom-up cascades by favoring generalist over specialist herbivores. PLoS ONE, 12, e0182766.

Wyckhuys KAG, Rauf A \& Ketelaar J (2015) Parasitoids introduced into Indonesia: Part of a region-wide campaign to tackle emerging cassava pests and diseases. Biocontrol News and Information, 35: 29N-38N.

Yonow T, Kriticos DJ \& Ota N (2017) The potential distribution of cassava mealybug (Phenacoccus manihoti), a threat to food security for the poor. PloS ONE, 12, p.e0173265. Zeddies J, Schaab RP, Neuenschwander P \& Herren HR (2001) Economics of biological control of cassava mealybug in Africa. Agricultural Economics, 24, 209-219. 


\section{Figure 1}

Map of Southeast Asia, depicting P. manihoti spatial distribution, infestation pressure and $A$. lopezi parasitism rates.

Doughnut charts in the left and right margins represent field-level incidence (i.e., red portion reflecting the proportion of $P$. manihoti affected tips, ranging from 0 to 1 for full circumference), and are complemented with bar charts indicative of plant-level $P$. manihoti abundance (i.e., average number of individuals per tip). The number inside each doughnut reflects the number of fields sampled per locale. Doughnut charts in the lower panel indicate average $A$. lopezi parasitism rate at six selected sites (depicted by the dark green section, reflecting proportion parasitism ranging from 0 to 1 for full circumference). The distribution map is created as overlay on a 2005 cassava cropping area (MapSpam, 2017). Photograph Anagyrus lopezi (credit G. Goergen, IITA).

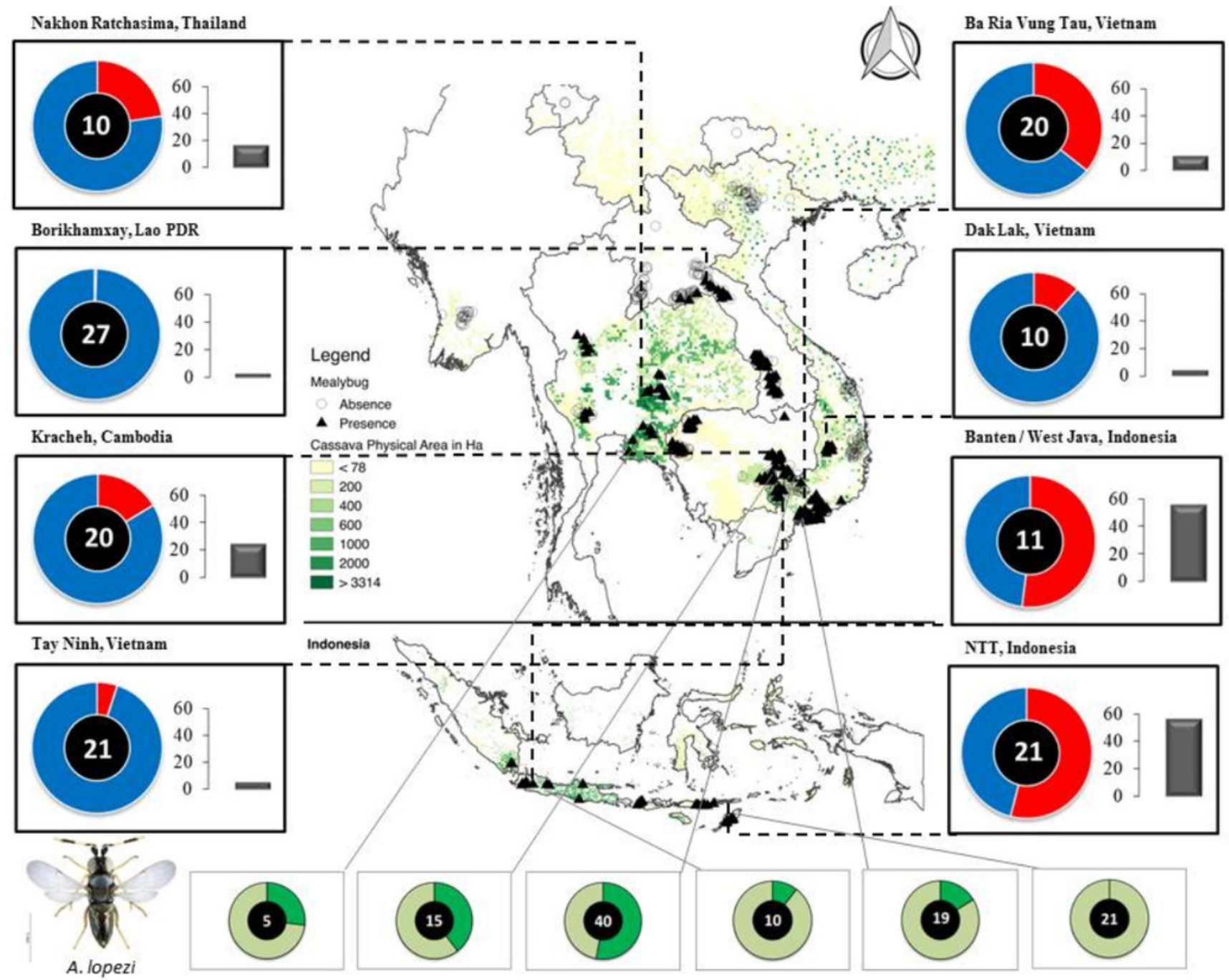




\section{Figure 2}

Bi-monthly mealybug population fluctuations in southern Vietnam, over a 2-year time period.

Phenacoccus manihoti dynamics are represented following the first record of $A$. lopezi presence in southern Vietnam, depicting field-level $P$. manihoti abundance $(n=8)$ as contrasted with respective $A$. lopezi parasitism rates, from July 2013 until July 2015.

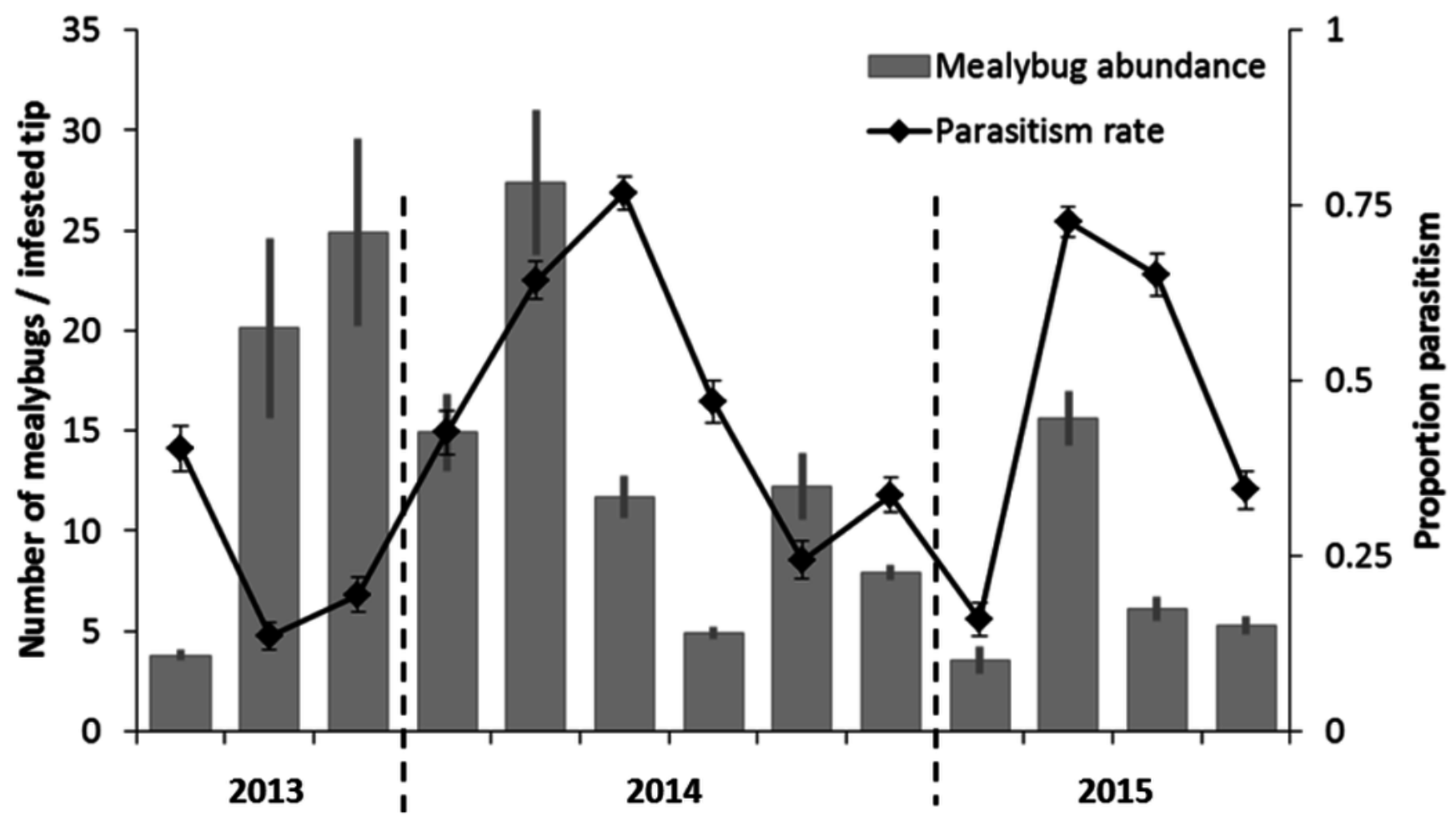


Figure 3

Effect of cassava mealybug parasitism rate on intrinsic rate of mealybug increase over consecutive 2-month periods in Tay Ninh, Vietnam.

Each dot represents a 2-month period in one of 8 field plots. Thin lines are linear regressions per each of the eight sites monitored for illustrative purposes although the analysis was done on the entire data set. The thick black line shows the fit of the entire data set. The red dotted line shows $r=0$; values above this on the $y$ axis indicate positive growth of mealybug populations and below it indicate negative population growth. Parasitism level above which $P$. manihoti growth rates are negative ranged between 0.38 and 0.69 for the 8 sites. See text for statistical details.

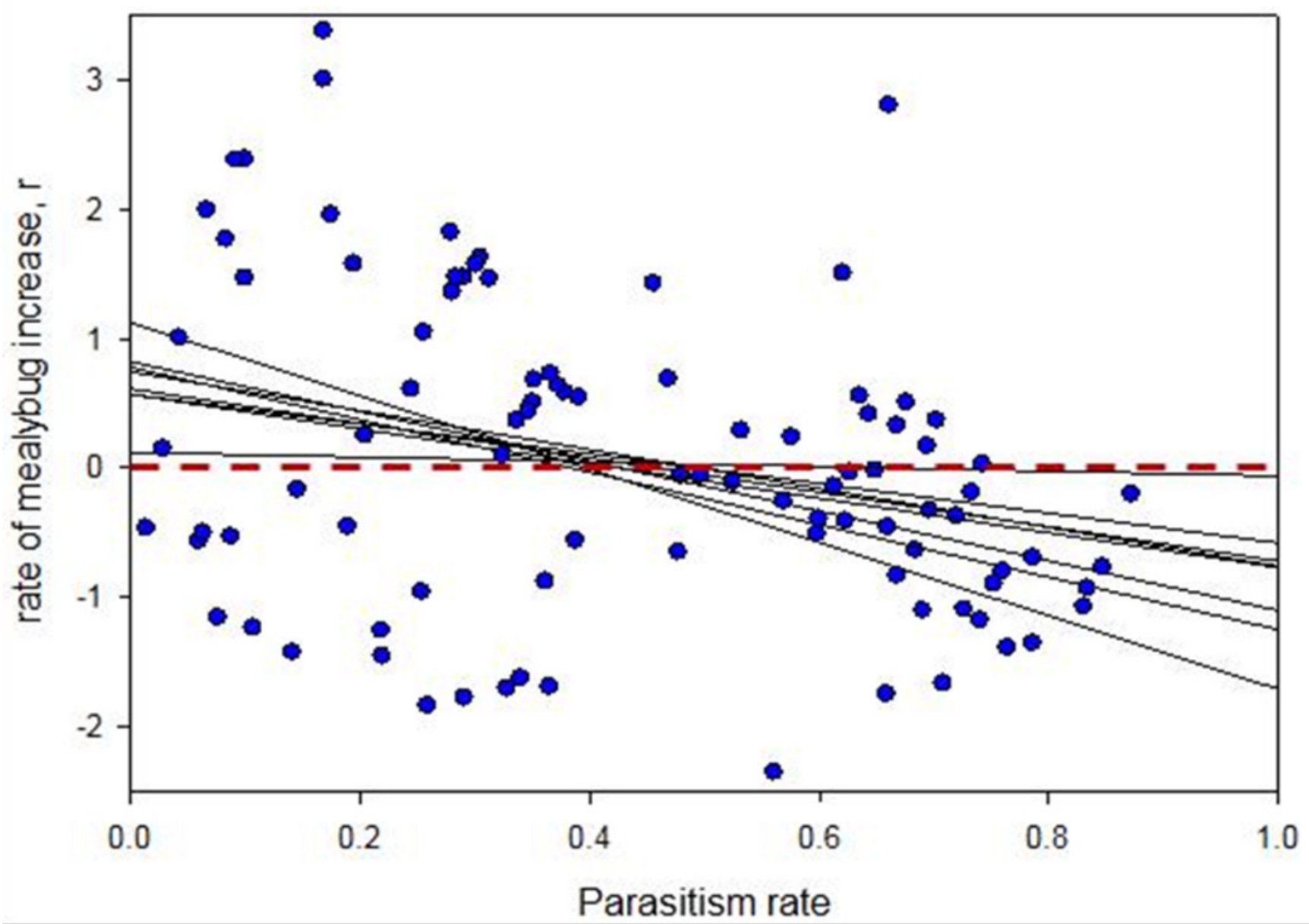




\section{Figure 4}

Mealybug abundance and subsequent yield parameters for two cassava varieties under an exclusion cage assay at Rayong, Thailand.

Six weeks after inoculation, mealybug abundance ( $n=16$; mean $\pm S E$ ) is compared between treatments for two common varieties (R72, KU50), and is significantly higher under 'full cage' conditions (i.e., exclusion of natural enemies, incl. $A$. lopezi), as compared to 'sham cage' and un-caged controls (ANOVA, $\mathrm{F}_{2,45}=50.289$, $\mathrm{P}<0.001$ for $\mathrm{R} 72 ; \mathrm{F}_{2,45}=9.807, \mathrm{P}<0.001$ for KU50). For each treatment, fresh root yield is determined at time of harvest, on a 12-month old crop.

A
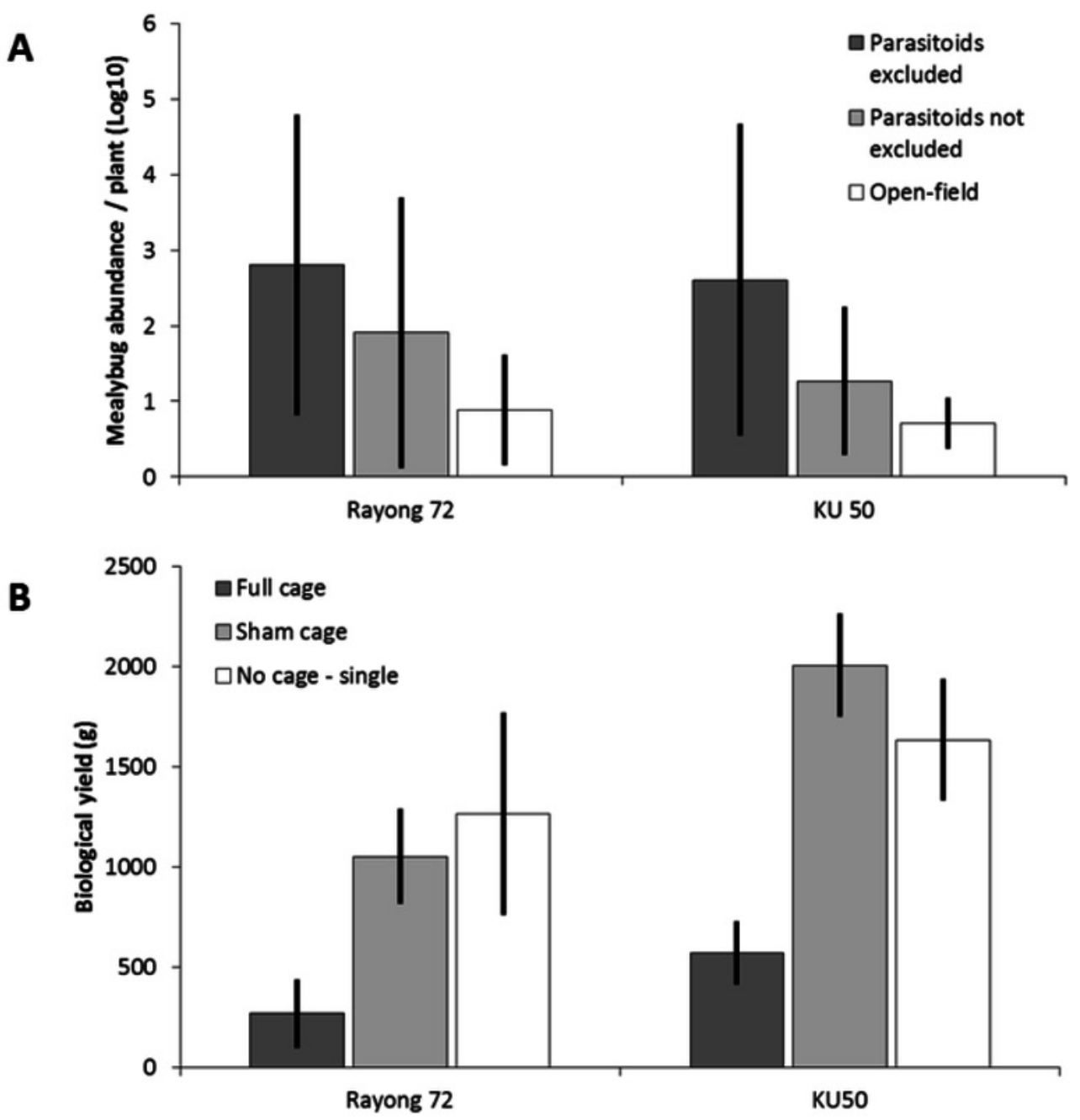
Figure 5

Annual percent shifts in crop yield for 51 cassava-growing provinces in Thailand, reflective of the mealybug invasion and ensuing biological control.

Shifts (A-D) cover the country-wide spread of $P$. manihoti from late 2008 until 2011, the first small-scale release of $A$. lopezi (Nov. 2009) and subsequent nation-wide distribution of the parasitoid from June 2010 onward. Province-level yield shifts depict the percent change of crop yield in one given year, as compared to the previous year.

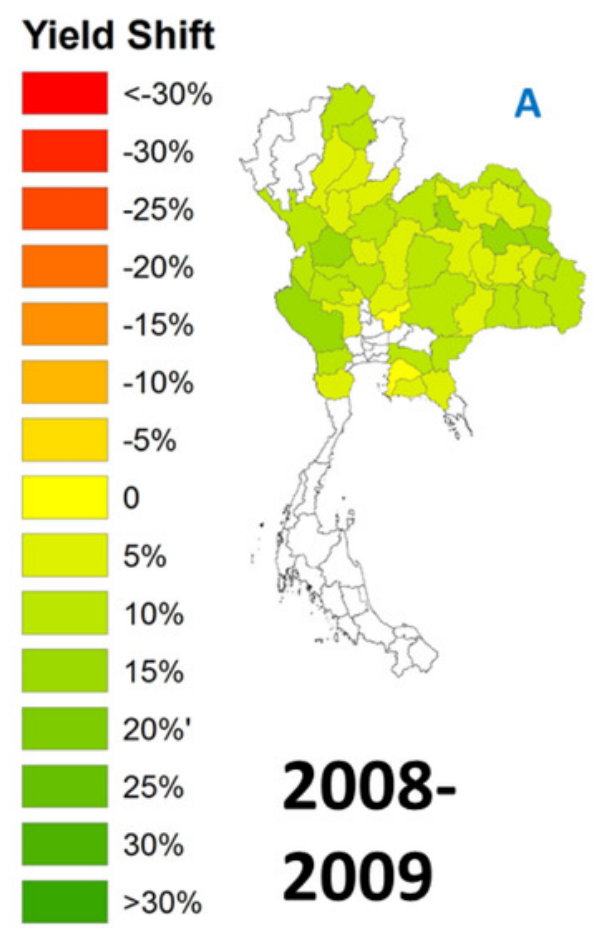

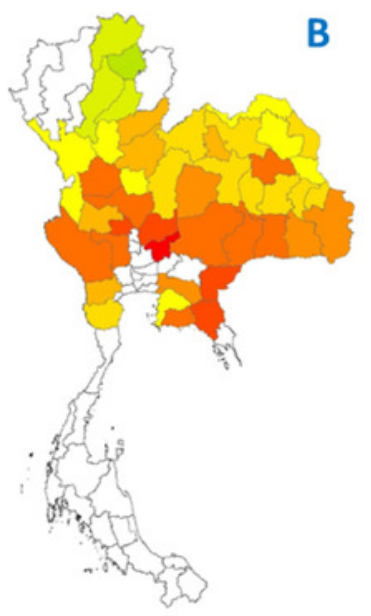

2009-

2010

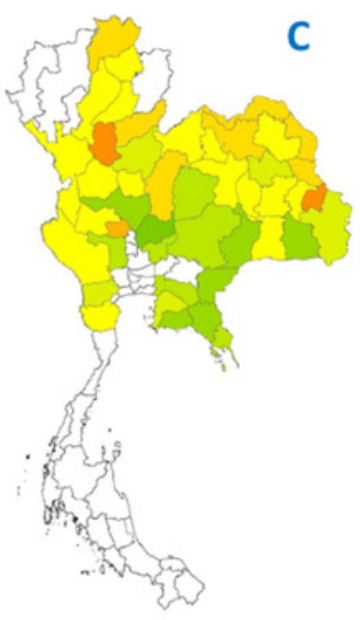

2010-

2011

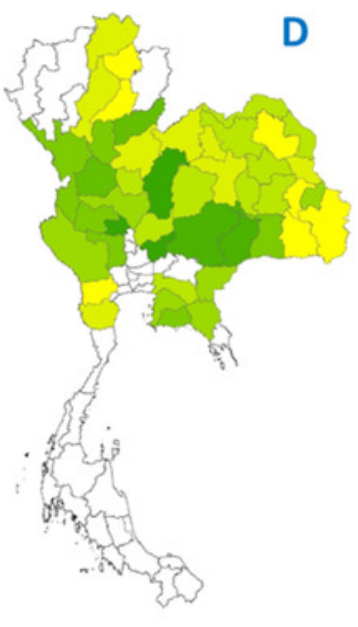

2011-

2012 